\title{
Research on the Problems and Countermeasures of the Construction of Scientific and Technological Innovation Platform in Colleges and Universities in Jilin Province
}

\author{
Xijun $\mathrm{Ou}^{1, \text { a }}$ and Qingyan Wang ${ }^{2, b}$ \\ ${ }^{1}$ Scientific Research Office, Jilin Engineering Normal University, Changchun, China \\ ${ }^{2}$ Power Supply Company, Jilin Petroleum Group Ltd., Jilin, China \\ a287460790@qq.com, b435218270@qq.com
}

Keywords: Scientific and technological innovation platform; Construction; Problems and countermeasures; Colleges and universities; Jilin province

\begin{abstract}
One of the most important links in current development of China's scientific and technological innovation system is to establish a scientific and technological innovation platform in universities, which is also a key part of scientific and technological innovation in Chinese universities. Its purpose is to integrate various resources of scientific and technological rationally for scientific allocation and confluence of research achievements. Such a platform may further the optimization of a university's scientific and technological research administration and operation mechanism, and guide and control relevant activities and transformation of scientific achievements in the university. This will even help a university adapt to current innovation and development in scientific and technological in other universities at home and abroad, and will link the scientific innovation system in higher education with that of the state effectively. In this paper, an analysis was made of the construction of such a platform in the universities in Jilin Province with the aim of formulating effective solutions to certain problems so as to aid the construction of the platform and improve a university's teaching and other comprehensive competence.
\end{abstract}

\section{Introduction}

The development of scientific and technological innovation is considered the most important part in China's social development, for it is a prerequisite for both the country and the nation, a key factor to improve China's social productivity and comprehensive strength, and a foundation for a stable and sustainable social development. As a result, a university in Jilin Province has to promote the construction of its platform for scientific and technological innovation, esp., its capability in independent innovation and core competitiveness. Only in this way is a university able to improve its comprehensive strength to become an important part of China's scientific and technological innovation system, generate more innovation-oriented graduates and enable the whole society to accomplish a healthy and sustainable development.

\section{Significant Elements in the Construction of Scientific and Technological Innovation Platforms in the Universities in Jilin Province}

Analysis of Hard Elements. The section headings are in boldface capital and lowercase letters. Second level headings are typed as part of the succeeding paragraph (like the subsection heading of this paragraph). Hard elements for the platform mainly include those hardware facilities, or laboratory equipment in other words, involved in the platform like investment, procurement, maintenance and management of laboratory equipment. Firstly, sufficient investment is necessary for timely adjustment and renewal of laboratory equipment since it is the most important step in a university's procurement of effective scientific and technical facilities. A university has to negotiate with relevant authorities and make up reasonable decisions on fund allocation. Secondly, laboratory equipment has to be perfected by new equipment purchasing as a guarantee of scientific research. It demands that a 
university has to procure equipment according to its own needs to enable related experiments to be completed as required. Thirdly, laboratory equipment has to be subject to proper maintenance because it is a major factor of its useful life. As overuse of equipment may shorten its life, leaving it idle for a long time will increase maintenance cost. It indicates that laboratory equipment should be maintained properly to extend its useful life and lower maintenance costs simultaneously. Finally, these hardware resources should be shared among different departments through effective management in compliance of a set of equipment management regulation so as to make best use of their values.

Analysis of Soft Elements. Soft elements for the platform include those factors which may affect the platform's developmental potentials and influences like culture, values and operational systems, etc. They are in fact an extension of hard elements. Firstly, they will further international academic exchanges and cooperation, by which a university may be aware of latest international scientific and technical development and the gaps between itself and other schools, and improve its cultivation of high quality talents with versatility. Secondly, they are helpful with mutual communication and learning between researchers so that they can renew their knowledge and abridge the gaps between other scholars and themselves guided by the principle of "Go Out and Invite In". Thirdly, these elements will help with the cultivation of researchers with high qualities and high level. A university should pay attention to fostering researchers' quality in morality by creating favorable academic environment through academic exchanges and communication which will improve their team spirit. At the same time, a university should endeavor to promote their professional competence and broaden their scope of knowledge, which will further the construction of the scientific and technological innovation platform in turn. Finally, relevant systems formulated by a university are also a part of these soft elements. To establish an effective platform for scientific and technological information, a university has to set down a scientific management system involving innovations on the structure and management of the platform, the system of faculty employment and other systems related to the platform to ensure the success of the platform.

\section{An Analysis of Major Problems in the Construction of Scientific and Technological Innovation Platforms in the Universities in Jilin Province}

Unevenness in Distribution and Redundancy in Variety. The distribution of key labs, engineering labs and engineering research centers at the provincial level shows that the proportion of this type of platforms keeps dropping, which indicates that many universities overstress fundamental theoretical researches but neglect the significance of applied engineering technology during platform construction, resulting in the shrinkage of effective researches of applied engineering technology. Besides, a well-known fact is that most of these platforms are based on government investment and located in those key universities in the province. As a result, other universities are always short of funds for governments both at the state and the provincial level seldom turn their eyes upon them, leading to the unevenness of higher education development in the province.

Repetition in Platform Construction in Some Universities. There is a tendency that the construction of platforms at a lower level follows those at a level above, e.g. a platform at the provincial level is always founded similar to a platform which is supported by the state government, and it is also true of the relationship between the platforms at the departmental level and the ones at the provincial level. The repetition of construction at different levels has given rise to the fact that one researcher may be appointed to several posts simultaneously so that only a small part of funds will be invested in labor and intellectual efforts. In some universities, more than 5 platforms are established at the provincial or departmental level, but very few teams undertake the responsibilities of construction. The repetition will neither give full play to the advantages of nor help with the construction of these platforms for a huge waste of resources.

Shortage of Awareness of Resource Sharing. Current administrative mechanism determines that the platforms at different levels in universities are under control of different governmental departments, resulting in the phenomenon that the functions and sources of supporting funds of the 
platforms show a strong tendency so that resources fail to be invested in different universities or research teams. In addition, some platforms are based on a certain university or a certain school of department in it, leading to the fact that some scientific assets are possessed by certain sections and the defect that scientific and technical resources are restrained in the application. In brief, the shortage of awareness of resource sharing has led to the differences of resource application in final scientific and technical innovation.

\section{Strategies for the Construction of Scientific and Technological Platforms in the Universities in Jilin Province}

Making a Distinction between the State-level Platform and the Ones at the Provincial Level. A distinction should be made for the development between state and local platforms. For the state-level platforms, they should be oriented to international frontier of fundamental researches and directed to resolve those issues of great importance for the country, while local platforms should take local peculiarities and industries with advantages into consideration and extend themselves to those areas which have not been covered by those state-level platforms. Such a practice will give full play to the advantages of the platforms at different levels and demonstrate their varieties and differences. Besides, the relation between the state-level platforms and the ones at the provincial level should be further reinforced to synchronize the construction and sharing of these platform resources so that the construction of the platforms at the lower level as a whole will be promoted on the basis of that of the platforms at the upper level. To sum it up, a scientific and technological innovation platform should conduct essential and scientific and technical researches effectively through analyses of important issues at the scientific frontier and in social development on the basis of cooperation with relevant research institutes and large enterprises. This demands that they focus on the research in natural sciences by using excellent innovation resources from different levels in a research environment with innovative academic atmosphere.

Planning the Classification of the Platforms for Overall Development in Compliance with State Policies. An overall analysis of the repetition of the innovation platforms has to be made both at the macro and at the micro level to guide and program related jobs. A definite plan should also be made on the classification of the platforms to avoid negative effects of repetitive supports upon platform construction. In order to make better use of China's resources in scientific and technological and prevent repetitive platform construction, relevant specifications should be formulated according to the requirements on the construction of platforms at different levels as well as related national policies and regulations. Firstly, the construction of the scientific and technological innovation platforms in universities should be standardized in the state top-level design and policy-making process according to China's particularities and major forms of the construction of such platforms. Secondly, provinces and ministries should reinforce the coordination between the state and local development to improve the inspection of platform construction and redesign the platform system for a sound allocation of resources of scientific and technological. This will help to avoid repetitive construction of the platforms. Thirdly, a university has to formulate an effective construction plan based on its own advantages and social demands. Central control over human and material resources should be executed to give full play to its potential in innovation of scientific and technological for the construction of new platforms.

Establishing an Information Disclosure Mechanism for University Innovation Platforms of Science and Technology. The government of Jilin Province should guide local universities and enterprises as well as related research institutes to share relevant resources actively and effectively on the basis of its own economic development and demands over scientific research together with the advantages of local universities. It should formulate systems related to the procurement and registration of scientific research resources and establish a government-dominated repository of scientific research resources as a sharing platform to provide information related to platform equipment, open projects and research fruits, etc. to the society via an optimized and perfected 
information disclosure mechanism. This will not only settle down the conflicts among different areas but also make full use of the advantages and effects of these platforms and improve resource sharing. At the same time, it will better the construction of university innovation platforms and the stable development of universities themselves.

\section{Conclusion}

The construction of university innovation platforms of scientific and technological is not only an important part in future development of China's innovation system of scientific and technological, but also a key factor to improve the development of China's scientific and technical system and economic system. Hence, universities should attach great importance to the construction of such platforms and try to resolve the problems in current construction via scientific and rational strategies to lay a solid foundation for further growth of these platforms in China.

\section{Acknowledgements}

This Work was financially supported by a project of Jilin Provincial Philosophy and Social Science Planning - Current status and problems of the construction of university innovation platforms of scientific and technological in Jilin Province and relevant solutions (2016B135).

\section{References}

[1] L.L. Gao and S.J. Wang: Science and Technology, Vol. 3 (2016) No.16, p.323+325.

[2] Y.B. Zhang: Chinese University Science and Technology, Vol. 22 (2016) No.6, p.76-77.

[3] J. Yan: Research and Exploration in Laboratory, Vol. 31 (2012) No.7, p.376-379.

[4] R.Z. Li and L.L. Wu: Modern Industrial Economy and Informationization, Vol. 3 (2013) No.18, p.8-9.

[5] D.J. Lu: Chinese University Science \& Technology, Vol. 21 (2015) No.7, p.38-39.

[6] J.K. Li and L. Chen: Research on Laboratory Work in Colleges and Universities, Vol. 20 (2013) No.4, p.57-59.

[7] X. Li: Chinese University Science \& Technology, Vol. 18 (2012) No.5, p.14-15.

[8] F. Zeng: Construction of Science and Technology Innovation Platform (Ph.D., Hunan Agricultural University, China 2014), p.28.

[9] X.Q. Heng and X.M. Wei: Science Technology and Industry, Vol. 11 (2011) No.8, p.145-147.

[10] Y. Fu: R \& D Management, Vol. 27 (2015) No.1, p.84-91. 